\title{
Desigualdade na oferta de crédito regional a pessoas jurídicas: uma análise em painel para o período 2000-2011 *
}

\author{
Leonardo Dondoni Dutra ** \\ Júlio Cesar Albuquerque Bastos *** \\ Marcos Tostes Lamonica ${ }^{* * * *}$ \\ Carmem Feijo ${ }^{* * * * *}$
}

\begin{abstract}
Resumo
O objetivo deste artigo é apresentar um estudo empírico sobre o comportamento do crédito bancário para pessoa jurídica em termos regionais no período 2000-2011 utilizando-se um modelo de dados em painel. Com as estatísticas do banco de dados Estatísticas Bancárias por Municípios - Estban e do Sistema Gerenciador de Séries Temporais do Banco Central do Brasil, foi possível construir as variáveis do modelo desenvolvido para explicar os determinantes do crédito às pessoas jurídicas por regiões. Apoiado na literatura pós-keynesiana, os resultados do modelo econométrico estimado comparando regiões apontam para a existência de um paradoxo financeiro da eficiência social, ou seja, observa-se este paradoxo quando instituições financeiras registram maior preferência pela liquidez indicando que o processo de geração de contratações de meios de produção e alocação de renda, que deveria ser iniciado pela disponibilidade de crédito, não é ratificado. Tal fato acaba por criar prerrogativas para inserção de políticas públicas para ocupar o hiato financeiro e promover a expansão econômica regional.
\end{abstract}

Palavras-chave: Firma bancária; Desigualdade regional; Preferência pela liquidez; Crédito regional; Dados em painel.

\begin{abstract}
Regional inequality in the supply of bank credit to firms: a panel data analysis of the period 2000-2011

The aim of the paper is to present an empirical study about the regional behavior of the bank credit to firms in the 2000-2011 period using a panel data model. The variables used in the model were obtained from two statistical data banks currently disseminated by the Brazilian Central Bank. Based on postKeynesian literature, the regional results of the econometric model confirmed, what we call, the existence of a financial paradox of social efficiency. This paradox means that the higher liquidity preference observed in the less developed regions, implies that potential and actual productive resources
\end{abstract}

* Artigo recebido em 14 de outubro de 2012 e aprovado em 8 de agosto de 2015. Os autores agradecem os profícuos comentários dos pareceristas anônimos, isentando-os de quaisquer falhas ou omissões que ainda persistam.

${ }^{* *}$ Economista da Eletrobrás / Doutorando no Programa de Pós-Graduação em Economia da Universidade Federal Fluminense (PPGE-UFF), Niterói, RJ, Brasil. E-mail: leo.dondoni@ig.com.br.

**** Professor Adjunto da Universidade Federal Fluminense (UFF), Niterói, RJ, Brasil. E-mail: julio_bastos@globo.com.

***** Professor Adjunto da UFF. E-mail: marcostostes@yahoo.com.

***** Professora Titular da UFF / Bolsista de produtividade CNPq (Conselho Nacional de Desenvolvimento Científico e Tecnológico), Niterói, RJ, Brasil. E-mail: cbfeijo@gmail.com. 
are idle, and so the social functionality of the bank is not fulfilled in the region. This behavior calls for public policies to reduce the financial gap and promote economic growth in less developed regions.

Keywords: Banks; Regional inequality; Liquidity preference; Regional credit; Panel data. JEL E44, O16.

\section{Introdução}

Na tradição keynesiana, são os bancos, por meio de sua disposição em ofertar crédito, que determinam, em última instância, o ritmo da atividade econômica. A decisão de conceder crédito viabiliza um volume de investimento acima da poupança e, consequentemente, maior crescimento do produto ${ }^{1}$. Nessa perspectiva, em tese, presume-se que o desenvolvimento do setor bancário exerce um papel proeminente no processo de crescimento e no desenvolvimento econômico de um país ou região. Ademais, ao ofertar crédito, a firma bancária, utilizando de sua prerrogativa singular de captadora de depósitos junto ao público, cria moeda. $\mathrm{Na}$ tradição keynesiana a moeda não é neutra, pois afeta o nível de produção e, consequentemente, o volume de emprego e renda. A não neutralidade da moeda decorre da hipótese de que decisões são tomadas sob incerteza não probabilística e, portanto, comportamentos racionais são pautados pela preferência pela liquidez. Isto implica dizer que mesmo que a autoridade monetária injete moeda na economia, nada garante que os volumes de emprego e renda gerados sejam os de equilíbrio de pleno emprego, pois, uma parte da oferta da moeda depende do estado de preferência pela liquidez dos bancos. Assim, quanto maior a preferência pela liquidez dos bancos, implicando maior racionamento do crédito, maior o desemprego.

Um aprofundamento dos argumentos de Keynes sobre o papel dos bancos em economias monetárias leva a que se interprete o crescimento desigual de regiões como relacionado ao desenvolvimento desigual do setor bancário e de sua atuação, e de uma forma geral, do setor financeiro. Indo além, pode-se dizer que o crescimento desigual entre regiões de um mesmo país pode ser explicado pelo fato de que regiões mais desenvolvidas tendem a apresentar menor preferência pela liquidez e melhores oportunidades de investimento e consequentemente de expansão da riqueza, do que regiões menos desenvolvidas economicamente (Dow, 1982; 1990). Assim, o desenvolvimento desigual das regiões pode ser associado ao volume

(1) Keynes (1930) discutiu com profundidade o papel dos bancos e o problema da liquidez mostrando que bancos não são meros repassadores de poupança, mas têm uma atuação ativa no sistema produtivo. Com a introdução do princípio da demanda efetiva na Teoria Geral do Emprego, Juro e da Moeda (1936), Keynes inverteria o papel da poupança como fonte de fundos para os investimentos em relação ao pensamento econômico dominante à época. Esta inversão na relação de causalidade entre poupança e investimento trouxe profundas consequências para o entendimento de como bancos e firmas interagem e, portanto, sobre o papel do sistema bancário no desenvolvimento de um país ou região. Assume-se, assim, que a oferta de crédito é um importante propulsor do crescimento econômico na medida em que fornece corpo de sustentação à demanda agregada. 
de crédito ofertado pelas instituições financeiras, as quais agem conforme a preferência pela liquidez de suas filiais nas diversas regiões onde atuam.

Analiticamente será argumentado que a eficiência do sistema financeiro, via atuação bancária, não deve ser avaliado somente pela sua eficiência operacional. Dessa forma, propõe-se que se leve em conta a eficiência social, ou seja, o impacto de sua atuação sobre o crescimento e o desenvolvimento econômico em uma região. Nesse contexto, bancos podem ser além de eficientes do ponto de vista microeconômico, também funcionais ao orientar a aplicação de recursos destinados às inversões produtivas. A atuação da firma bancária em promover crédito é precursora e viabilizadora de processos de contratações de meios de produção e, posteriormente, criação de renda, ou seja, essas instituições financeiras podem trazer consigo uma responsabilidade social - entendida como o elo de ligação do sistema financeiro bancário em prover crédito e ser eficiente do ponto de vista social ao gerar renda e promover o desenvolvimento econômico.

No entanto, se a atuação regional dos bancos não se traduz em mais prosperidade econômica, então pode-se argumentar que o comportamento da firma bancária leva a um paradoxo financeiro da eficiência social, ou seja, cria-se uma ruptura nos processos de contratações de meios de produção e criação de renda. Esta ruptura ocorre dado um reposicionamento da firma bancária em direção a ativos financeiros mais líquidos que não o crédito empresarial. Dessa forma, abrir-se-ão argumentos favoráveis de inserção de políticas públicas com finalidades de introdução de instrumentos financeiros para que catalizem e/ou incentivem as diversas demandas efetivas regionais. Como forma de superação desse gargalo, bancos públicos regionais poderiam ser utilizados como mecanismos de ocupação do hiato financeiro que as regiões menos desenvolvidas econômica e financeiramente apresentam.

Com base na literatura pós-keynesiana, o objetivo deste artigo é apresentar um estudo empírico sobre o comportamento do crédito bancário para a pessoa jurídica no âmbito nacional e regional no período 2000-2011. A elevada desigualdade no desenvolvimento regional brasileiro é objeto de pesquisa recorrente na nossa academia ${ }^{2}$. A literatura econômica sobre o papel do sistema financeiro em relação às desigualdades regionais tem sido objeto de pesquisa mais recente, destacando-se trabalhos como os de Amado (1997), Crocco (2003), Crocco e Jayme (2006), dentre outros. A contribuição deste trabalho para a literatura da desigualdade econômica entre as regiões é explorar especificamente os determinantes da oferta de crédito por regiões brasileiras nos anos 2000. O modelo econométrico apresentado, inspirado teoricamente na literatura pós-keynesiana, explica com sucesso os

(2) Ver, por exemplo, Furtado (1966; 1972), como trabalhos clássicos sobre o tema da desigualdade regional no Brasil. 
determinantes do crédito para empresas nas regiões, confirmando a hipótese de que regiões menos desenvolvidas apresentam maior preferência pela liquidez, o que reforça as desigualdades regionais. Neste sentido, as questões que este artigo se propõe a responder são: (i) identificar as variáveis relevantes como determinantes do crédito para pessoa jurídica nas regiões geográficas; (ii) comparar a importância relativa dessas variáveis para explicar os determinantes da oferta de crédito regional; (iii) verificar se os bancos agem de forma discricionária nas regiões geográficas brasileiras.

O presente artigo é composto de cinco seções, incluindo esta introdução. A primeira seção aborda brevemente o papel dos bancos em economias monetárias. Na segunda seção estão listados os estudos sobre a atuação dos bancos a nível regional, além da discussão do papel da preferência pela liquidez e do paradoxo financeiro da eficiência social. Na terceira seção estão os indicadores selecionados para a análise empírica. $\mathrm{Na}$ quarta seção encontram-se os procedimentos metodológicos e os resultados das estimações do modelo. Por fim, apresentam-se as considerações finais.

\section{0 papel dos bancos em economias monetárias}

Teoricamente, na visão keynesiana, a importância dos bancos no sistema econômico é explicada pelo processo de financiamento do investimento das firmas que é entendido por meio do circuito finance- investimento- poupança-funding. Por meio deste circuito, os recursos iniciais para a execução de novos planos de investimento não necessariamente dependem de poupança prévia, pois podem ser oriundos da criação de meios de pagamentos pelos bancos. Logo, a ênfase é como os recursos podem ser alocados em ativos de maturidades diversas, os quais apresentam diferentes taxas de retorno e graus de liquidez ${ }^{3}$. Assim, entende-se que a maior ou menor preferência pela liquidez, que explica a postura dos bancos na oferta de crédito, seria um reflexo da racionalidade dos agentes que operam em economias monetárias.

Nesse sentido, o posicionamento no debate sobre o papel dos bancos no processo de desenvolvimento se aprofunda na questão do grau de desenvolvimento do mercado financeiro que não deve ser confundido com o peso do sistema

(3) No primeiro caso, considera-se que ao realizar o investimento, o processo do multiplicador gera expansão da renda e, por conseguinte, expansão da poupança agregada. No modelo do circuito finance-funding, esta expansão da poupança deve se transformar em compra de títulos de empresas em mercados primários de títulos financeiros, permitindo a essas empresas transformar suas obrigações de curto prazo (empréstimos bancários) em passivos de longo prazo (debêntures e ações). Nesse sentido, há a necessidade de um mercado financeiro desenvolvido, que permita que as empresas colocoquem seus títulos de longo prazo, o que reduziria a vulnerabilidade financeira dos investidores e da economia como um todo. Quanto menos desenvolvido o mercado financeiro, menor o funding, e assim maior será o problema de descasamentos entre ativos e passivos aumentando o risco imposto ao processo. 
financeiro dentro da estrutura produtiva. Isso porque é possível observar em muitas economias, em particular as em desenvolvimento, que o peso dos ativos bancários no total de riqueza é elevado, e isto pode não significar que recursos estejam sendo alocados para o circuito finance-investimento-poupança-funding. Studart (2005) apresenta uma qualificação importante ao papel dos bancos e do sistema financeiro para o entendimento do funcionamento do circuito financeiro em economias em desenvolvimento. Esse autor introduz a ideia de funcionalidade desse sistema, ou seja, que o seu grau de desenvolvimento seja medido pelo seu papel funcional em fornecer finance e funding aos setores produtivos e não pelo seu tamanho.

Um contraponto interessante do circuito keynesiano finance-funding à luz da literatura novo-keynesiana pode ser visto na análise entre sistema financeiro e crescimento econômico proposta pela literatura conhecida como finance-growth nexus. Nesta literatura, enfatiza-se a relação positiva do grau de profundidade do sistema financeiro (bank deepening) e do desenvolvimento econômico (Levine, 2010). Em consequência, advoga-se que a eficiência microeconômica da alocação ótima de recursos acabe por levar à eficiência macroeconômica. Pela literatura póskeynesiana, assumindo que bancos agem de forma discricionária conforme sua preferência pela liquidez, não necessariamente a eficiência bancária ao nível microeconômico equivale à maior funcionalidade (no sentido de alimentar de forma equilibrada o circuito finance-funding) ao nível macroeconômico, nem mesmo de promover o desenvolvimento econômico no sentido de viabilizar o uso de recursos ociosos em regiões menos desenvolvidas, ou seja, de apresentar funcionalidade do ponto de vista social.

A existência de assimetria de informações como uma das principais falhas de mercado com efeitos particulares nos mercados bancário e financeiro, tema abordado originalmente por Stiglitz e Weiss (1981) ${ }^{4}$, oferece a explicação microeconômica para o racionamento do crédito como um comportamento racional do sistema financeiro. Contudo, como mostrado por Crocco et al.. (2011, p. 301), a atuação da firma bancária microeconomicamente eficiente, orientando suas decisões segundo sua preferência pela liquidez, não conduz necessariamente a uma melhor eficiência na alocação dos ativos bancários, do ponto de vista macroeconômico ${ }^{5}$. Nesse contexto, pode-se argumentar que existe uma

(4) A assimetria de informações entre emprestadores e tomadores se acentua por meio da seleção adversa e do risco moral. A combinação de ambos produz um setor financeiro que, deixado aos princípios das leis de mercado, atingirá um resultado menos que perfeito, impondo restrições ao crédito, dificultando, assim, o acesso aos recursos necessários para a realização de novos projetos de investimentos.

(5) Isto porque o racionamento do crédito não tem por origem apenas a falta de informação, mas principalmente a busca pela maior rentabilidade do setor financeiro, dada a percepção de risco de suas aplicações pelos agentes financeiros em relação ao futuro desconhecido. 
intransitividade entre a eficiência microeconômica da firma bancária e a geração recursos para o desenvolvimento econômico ${ }^{6}$.

Indo mais além, Dymski (2007) mostra que a ênfase na eficiência bancária deve ser reduzida, pois a função da firma bancária deve levar em conta sua capacidade de gerar bem estar social por meio da geração de recursos destinados às inversões produtivas. Assim, segundo o autor, o termo eficiência bancária deve ser avaliado tanto do ponto de vista operacional como também do social. Sob esta perspectiva, abre-se a prerrogativa de qual será o papel socialmente desejável de atuação da firma bancária, dado que suas decisões são proeminentes ao processo de contratação de meios de produção e posteriormente criação de renda. Se a questão for válida então abrir-se-ão argumentos favoráveis de inserção de políticas públicas com finalidades de inserção de instrumentos financeiros para que catalisem e/ou incentivem as diversas demandas efetivas regionais.

A próxima seção, além de abordar a literatura do papel dos bancos no desenvolvimento econômico focando a preferência pela liquidez, irá também descrever de forma sistemática o paradoxo financeiro da eficiência social como também a justificativa de inserção de políticas públicas para que o paradoxo seja evitado.

\section{O papel dos bancos no desenvolvimento regional}

A partir dos anos 1980, começaram a ser desenvolvidos estudos versando sobre temas como o impacto diferenciado das taxas de juros e dos fluxos interregionais de fundos sobre as regiões, e sobre a disponibilidade regional de crédito em geral. A hipótese é a de que a disponiblidade de crédito regional é um importante propulsor do crescimento econômico na medida em que impulsiona a demanda agregada nas diferentes regiões de um país. Estudos, em sua maioria de caráter póskeynesiano (Amado, 1997; Chick, 1986; Dow, 1982, 1990; Rodriguez-Fuentes, 1996; Crocco; Jayme Jr., 2006; Cavalcante; Crocco; Jayme Jr., 2006; dentre outros), argumentaram que os bancos locais influenciam o desenvolvimento regional de forma positiva ou negativa ao afetarem a disponibilidade local de crédito. Portanto, as finanças atuariam também de modo indireto sobre o desenvolvimento regional ${ }^{7}$.

(6) Supõe-se, assim, mesmo que o sistema bancário possua um total de ativo elevado em relação ao PIB, parcela considerável deste pode ser alocada no circuito financeiro em vez de no circuito produtivo. É por isso que se diz que a alocação de recursos pelos bancos pode não ter papel funcional, tal como sugerido pelo argumento de curto alcance que observa apenas a eficiência microeconômica do banco em uma economia monetária de produção.

(7) Conforme apontado por Crocco (2010), as mudanças ocorridas no sistema financeiro internacional a partir dos anos 1970 geraram maior interesse pelos aspectos do desenvolvimento financeiro das regiões. Segundo o autor, estudos, em sua maioria de caráter pós-keynesiano, argumentam que, sob mobilidade imperfeita de capitais, os bancos locais influenciam o desenvolvimento regional ao afetarem a disponibilidade local de crédito. Conclui-se, portanto, que a estrutura do sistema financeiro atuaria também sobre o desenvolvimento regional. 
O trabalho pioneiro de Dow (1982) mostra que o sistema financeiro regional juntamente com condicionantes do lado real da economia pode promover padrões de desenvolvimento regional desiguais. Isto porque: (a) bancos nacionais privados podem realizar menos empréstimos nas regiões pouco desenvolvidas, dada sua estrutura econômica e o controle sobre as suas filiais, e (b) devido a sua preferência pela liquidez, bancos regionais privados podem preferir manter um elevado nível de reservas e restringir os empréstimos locais nas regiões menos desenvolvidas. Assim, Dow destaca o papel relevante do crédito nos estudos econômicos regionais contemporâneos, aliando a análise dos determinantes do crédito à temática da desigualdade regional em sua distribuição.

A interdependência entre oferta e demanda de crédito regional é ponto-chave da teoria pós-keynesiana para defender o desenvolvimento de sistemas financeiros regionais. A oferta de crédito é influenciada tanto pela preferência pela liquidez quanto pelo estágio de desenvolvimento bancário (Cavalcante et al.., 2007, p. 92). Nesse contexto, dadas as expectativas, firmas bancárias criam moeda escritural ofertando crédito localmente, e consequentemente, ampliam sua base de depósitos. Dessa forma, podem alterar a liquidez de seu ativo em resposta a uma demanda de financiamento, afetando a economia real e, por conseguinte, o crescimento econômico regional. Porém, em um ambiente de maior incerteza e menor dinamismo econômico, os agentes se refugiarão na forma mais líquida de riqueza: moeda. Nesse contexto, a firma bancária pode não promover novas rodadas de financiamento, ocasionando, portanto, o racionamento de crédito, provocando uma ruptura do finance.

Uma suposta consequência dessa preferência pela liquidez maior em regiões economicamente menos desenvolvidas é que os bancos localizados nestas áreas perdem mais reservas do que os bancos que estão localizados nas áreas mais dinâmicas ${ }^{8}$. Por isso, emprestam menos e a uma taxa de juros mais elevada, o que inibe o investimento em capital fixo e torna a economia menos dinâmica, reforçando o ciclo de uma maior preferência pela liquidez e baixo crescimento. Dessa forma, infere-se que a disponibilidade de crédito e o crescimento econômico estão diretamente relacionados e, quanto mais desenvolvido o sistema financeiro, maior deverá ser o potencial explicativo do crédito no crescimento. Consequentemente, quanto maior o volume de crédito oferecido, mais dinamismo é injetado no processo produtivo 9 .

(8) A centralização do sistema bancário brasileiro impõe que todo o recurso destinado às outras aplicações que não o crédito seja concentrado na sede da instituição. Dessa forma, como o depósito à vista é a única fonte de recursos geridos pela agência, essas firmas bancárias em regiões menos dinâmicas estariam menos propensas a emprestar sob o risco de ficarem ilíquidas.

(9) Uma contribuição nesse sentido é levantada por Nogueira et al. (2014) em que verificaram que o caráter altamente concentrado do sistema bancário brasileiro produz uma tendência de concentração das agências bancárias na região mais desenvolvida. Os autores concluem que, embora esse padrão pudesse ser eficiente do ponto de vista dos bancos, não o é em relação ao desenvolvimento regional, aumentando suas disparidades econômicas frente às demais regiões mais desenvolvidas. 
Assim, as posturas dos bancos em relação ao ambiente de incerteza e aos riscos dos negócios podem se traduzir em maior ou menor preferência pela liquidez com base no estado das expectativas em relação às oportunidades de ganhos futuros. Desta forma, bancos administram suas aplicações avaliando o trade-off entre liquidez e rentabilidade ${ }^{10}$. Neste contexto, as relações entre bancos e firmas não são passivas, e bancos concedem empréstimos influenciados pela sua preferência pela liquidez, a qual é também influenciada pela avaliação acerca da capacidade das firmas em honrarem seus compromissos.

Myrdal (1968) reconheceu que os bancos desempenham papel relevante no processo de desenvolvimento econômico. Para ele, utilizando a ideia de causação circular cumulativa para explicar a divergência no processo de crescimento econômico entre países e regiões, os bancos poderiam exercer papéis tanto negativos como positivos ao ambiente econômico. Sob um papel negativo, os bancos atuam ampliando as desigualdades regionais ao transferirem poupanças das regiões mais pobres para as mais ricas. Por outro lado, sob um papel positivo de sua atuação, os bancos podem estender os efeitos da expansão econômica do centro desenvolvido para as outras regiões menos desenvolvidas. Dessa forma, como interpretação de papel positivo à la Myrdal, pode-se argumentar que o aumento de liquidez em regiões mais pobres poderia contribuir para reduzir disparidades econômicas.

Desse modo, Amado (1997) argumenta que o processo acumulativo da desigualdade econômica pode ser rompido por intermédio da atuação de políticas governamentais. A autora justifica, assim, a atuação dos bancos públicos em regiões de menor dinamismo econômico complementando o hiato de liquidez a fim de frear o aumento da preferência por liquidez. A atuação de bancos públicos deveria ser no sentido de promover a desconcentração do crédito para as regiões menos dinâmicas, estimulando o desempenho dessas regiões, supondo-se que, como consequência dessa política, ocorra elevação do investimento, aumentando o emprego e gerando renda. Cria-se, assim, um processo de causação circular cumulativo positivo, em que a maior oferta de moeda e o maior otimismo com as condições econômicas aos poucos faz diminuir a preferência pela liquidez da região ${ }^{11}$.

(10) De Paula e Alves Jr. (2003) enfatizam que bancos, com preferência pela liquidez, poderão não acomodar passivamente a demanda por crédito, pois buscarão comparar os retornos esperados com os prêmios de liquidez de todos os ativos que podem ser comprados. Isto implica que a disponibilidade de crédito poderá diminuir devido à maior preferência pela liquidez, sem estar necessariamente relacionada diretamente aos riscos inerentes aos empréstimos, fazendo com que o racionamento de crédito possa surgir independentemente dos retornos esperados dos projetos de investimento.

(11) Ferreira Jr.et al. (2012) discorrem sobre a estratégia de política pública de inclusão financeira para as regiões menos desenvolvidas via Sistema de Fomento e Financiamento do Desenvolvimento Local (SFDL) e também pelas agências de fomento como forma de complemento da oferta de recursos destinados às empresas. $\mathrm{O}$ principal diferencial está na capacidade de articulação e organização da oferta e demanda de microserviços financeiros, em nível local, para empreendedores ao estruturar e articular um sistema de finanças de proximidade adequado a cada situação. Dessa forma, o grande desafio dessa política pública é a adequação da capilarização via aumento de escala da oferta dos serviços financeiros como o microcrédito, micropoupança, microseguro e o crédito imobiliário. 
Se o sistema financeiro é o ponto de partida do processo de ratificação das demandas efetivas, então um redirecionamento dos bancos a posições mais líquidas, ou melhor, a um aumento da preferência pela liquidez, acabará por causar uma ruptura nos processos decisórios dos agentes. Dessa forma, todo o contexto que se desdobraria quanto às contratações de meios de produção como o investimento, mão de obra e geração de fluxos de renda, não sendo realizados, acabará por impor um rompimento desse processo de crescimento econômico. Esse mecanismo de ruptura acaba por impor às regiões menos desenvolvidas a manutenção de sua estagnação econômica vis-à-vis às regiões mais desenvolvidas. Nesse contexto, sendo válido o paradoxo financeiro da eficiência social, um aumento da preferência pela liquidez dos bancos em regiões menos dinâmicas leva à queda no processo de eficiência social dado o posicionamento defensivo dos agentes em não ratificar a expansão produtiva.

\section{Atuação dos bancos no período 2000-2011: indicadores selecionados}

As informações primárias para a elaboração da análise empírica foram obtidas a partir do balanço de agências bancárias disponíveis no banco de dados Estatísticas Bancárias por Municípios - Estban, do Banco Central do Brasil, para a construção de parte das variáveis explicativas ${ }^{12}$. Esta fonte apresenta dados mensais de agências bancárias presentes em 3.465 municípios do país, a partir dos anos 2000, sendo uma fonte empírica ainda pouco explorada para estudos de estimativa da oferta de crédito.

Considerando nossa perspectiva analítica, bancos são agentes ativos que administram os dois lados de seus balanços com o objetivo de maximizar lucros, e assim suas aplicações devem equilibrar rentabilidade com risco, conforme expectativas e o grau de confiança a ela associados. Não só os ativos podem estar sendo alocados fora do circuito produtivo, como também regiões mais dinâmicas tendem a apresentar mais oportunidades de negócios e, neste sentido, o bank deepening tende a reforçar desigualdades regionais e não diminuí-las. Nesta perspectiva, é de se esperar que a preferência pela liquidez dos bancos seja maior em regiões menos desenvolvidas.

O Gráfico 1 mostra a evolução da preferência pela liquidez de 2000 a 2011 pelas regiões. $\mathrm{O}$ indicador de preferência de liquidez foi definido como a razão entre depósito à vista do setor privado e do governo, dividido pelas operações de crédito total. A menor preferência de liquidez entre as regiões é observada na região Sudeste, sendo seguida pela região Sul. A região Norte apresentou a maior preferência de liquidez, que evoluiu de forma decrescente após 2002. Já a região Nordeste registrou

(12) O arquivo eletrônico ESTBAN, do Banco Central do Brasil, disponibiliza mensalmente informações da Estatística Bancária Mensal, contemplando a posição mensal dos saldos das principais rubricas de balancetes dos bancos comerciais e dos bancos múltiplos com carteira comercial, por município. 
crescimento da preferência pela liquidez até 2002 e ratificou a manutenção desse patamar até o final do período. Em geral, observa-se uma tendência à redução da preferência pela liquidez em todas as regiões quando comparada ao início da série. A marcante diferença no grau de preferência pela liquidez entre as regiões é um reflexo da desigualdade na distribuição do crédito no território nacional.

Gráfico 1

Brasil e regiões: Índice de Preferência pela Liquidez: 2000 a 2011

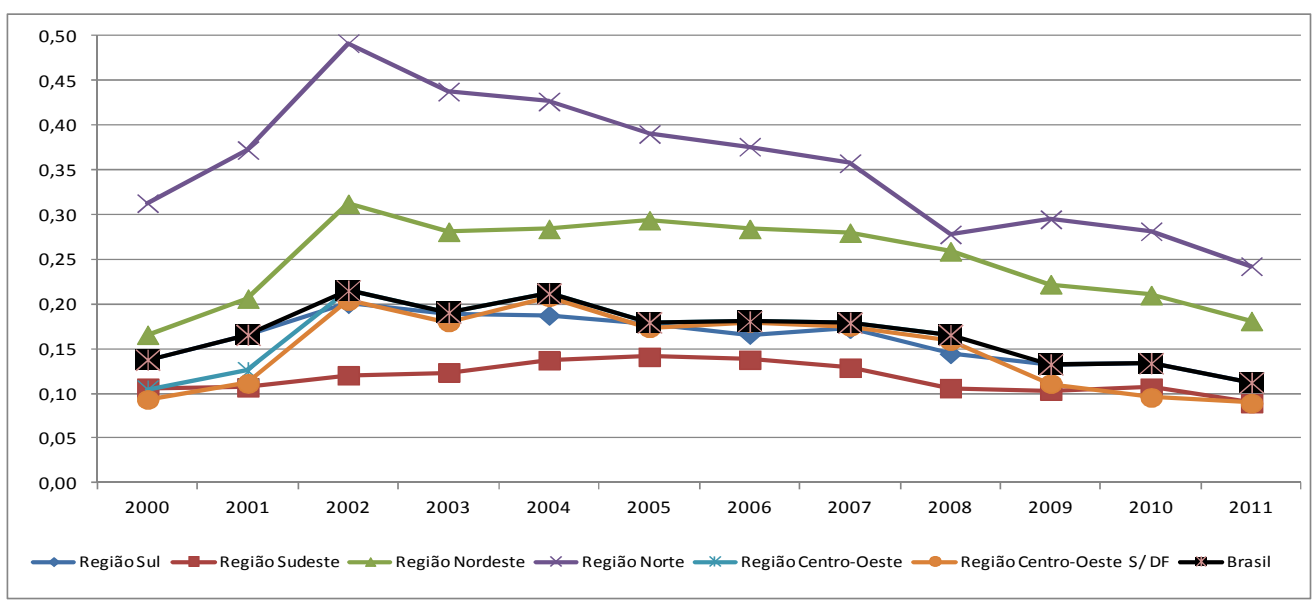

Fonte: Elaboração própria a partir dos dados do Estban-BCB, 2011.

O grau de desigualdade na oferta de crédito entre as regiões pode ser mensurado pelo índice regional de crédito (IRC) ${ }^{13}$. Este índice compara o quociente das participações da região no total de crédito concedido no país com a participação da riqueza/produto da mesma no PIB nacional. Quando o IRC é igual à unidade, a proporção de crédito aplicado na localidade é idêntica à proporção do PIB naquela localidade. Quando é maior que a unidade, a região tem uma participação na distribuição do crédito superior à sua participação na distribuição do PIB e, quando o IRC é menor que a unidade, a região tem uma participação na distribuição do crédito menor que sua participação na distribuição do PIB.

O Gráfico 2 apresenta a evolução do IRC para as regiões do país. Como esperado, a região Sudeste apresentou uma participação relativa do crédito muito superior à participação na distribuição da riqueza total em todo o período. As demais regiões apresentaram participação na distribuição do crédito menor que sua participação na distribuição do PIB, à exceção da região Centro-Oeste. Essa região, por concentrar as sedes das instituições públicas dos poderes executivo, legislativo

(13) Desenvolvido em Crocco (2010) e Crocco et al. (2011). Conforme Crocco et al. (2011), a metodologia aplicada ao IRC é uma adaptação do conhecido "quociente locacional”, amplamente utilizado na literatura de economia regional para determinar a existência ou não de especialização produtiva em uma região específica. 
e judiciário do país, apresenta características econômicas específicas fazendo com que os indicadores bancários dessa região sejam muito influenciados por outros fatores que não ligados à atividade produtiva ${ }^{14}$.

Gráfico 2

Índice Regional de Crédito (IRC): 2000 a 2011

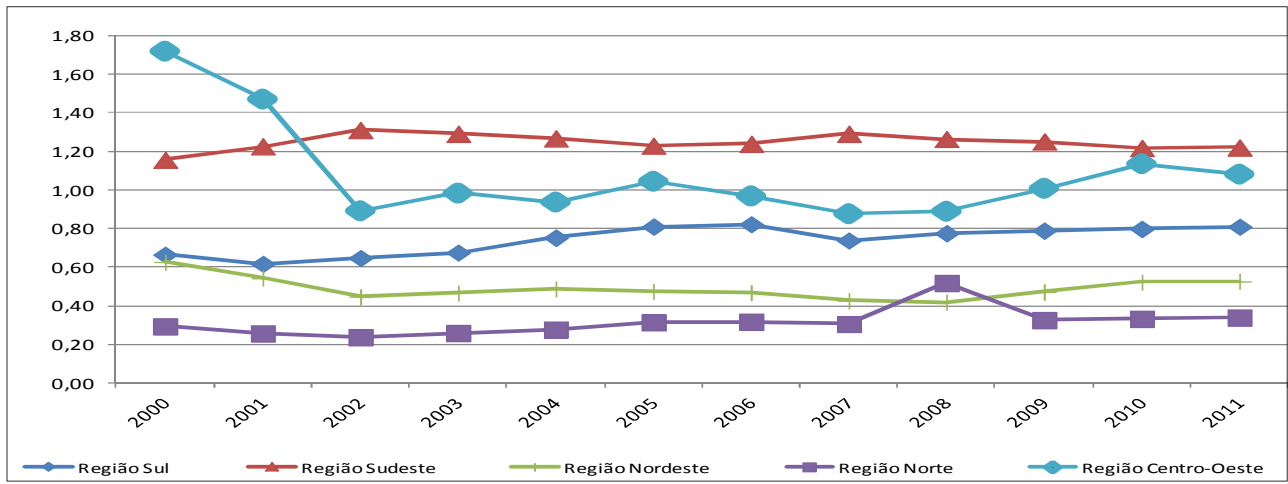

Fonte: Elaboração própria a partir dos dados do Estban-BCB e IBGE, 2011.

Uma medida de escala de operação do sistema bancário regional, ou seja, o peso da atividade bancária em cada região (Ativo das instituições bancárias/PIB), é mostrada no Gráfico 3. Essa razão é utilizada como um indicador proxy do grau de desenvolvimento do setor bancário localmente. As regiões Sudeste e Centro-Oeste foram as que apresentaram o indicador Ativo/PIB acima da média nacional apesar de apresentarem queda de participação.

Gráfico 3

Brasil e regiões: Razão Ativo/PIB \%: 2000 a 2011

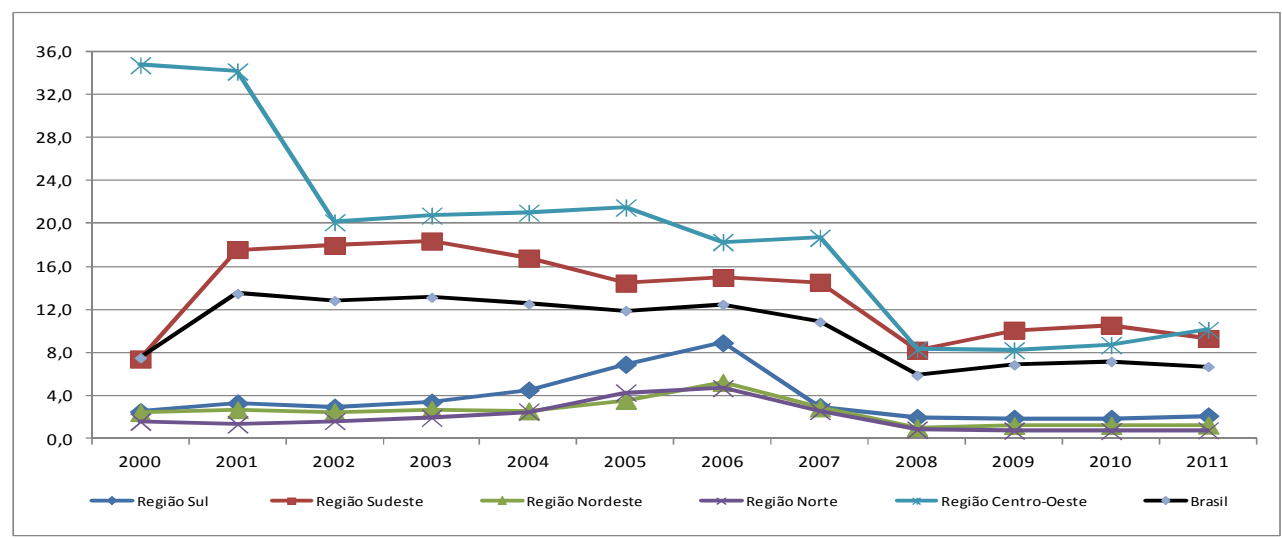

Fonte: Elaboração própria a partir dos dados do Estban-BCB e IBGE, 2011.

(14) Vasconcelos et al. (2004), com base nas evidências em relação à elevada concentração do crédito regional, conclui que a discussão sobre a baixa relação crédito bancário/PIB [Favor verificar se "relação de" não ficaria melhor neste caso] no Brasil deve envolver também questões regionais. 
A evolução dessa variável permite argumentar que houve um aprofundamento, ainda que moderado, da atividade bancária nas regiões Sul, Norte, Nordeste e Centro-Oeste. Após 2008, todas as regiões apresentaram decréscimo desse indicador, sendo que a região Sudeste apresenta uma inversão desse movimento. Nesse contexto, pode-se afirmar que os resultados positivos acima da média nacional e com potencial de recuperação pós-crises, deve-se ao fato de a região Sudeste ser a grande beneficiada com o processo de concentração bancária.

O Gráfico 4 apresenta a distribuição do passivo exigível (isto é, a soma dos depósitos privados à vista, depósitos à vista dos governos e depósitos à prazo) por região. Os dados mostram que a região Sudeste concentrou a maior parcela do volume de depósitos, alcançando mais de $60 \%$ do total em média no período, confirmando que as desigualdades estruturais reforçam-se em desigualdades financeiras, tendendo a ampliar as primeiras.

Gráfico 4

Participação do volume de depósitos por região: 2000 a 2011

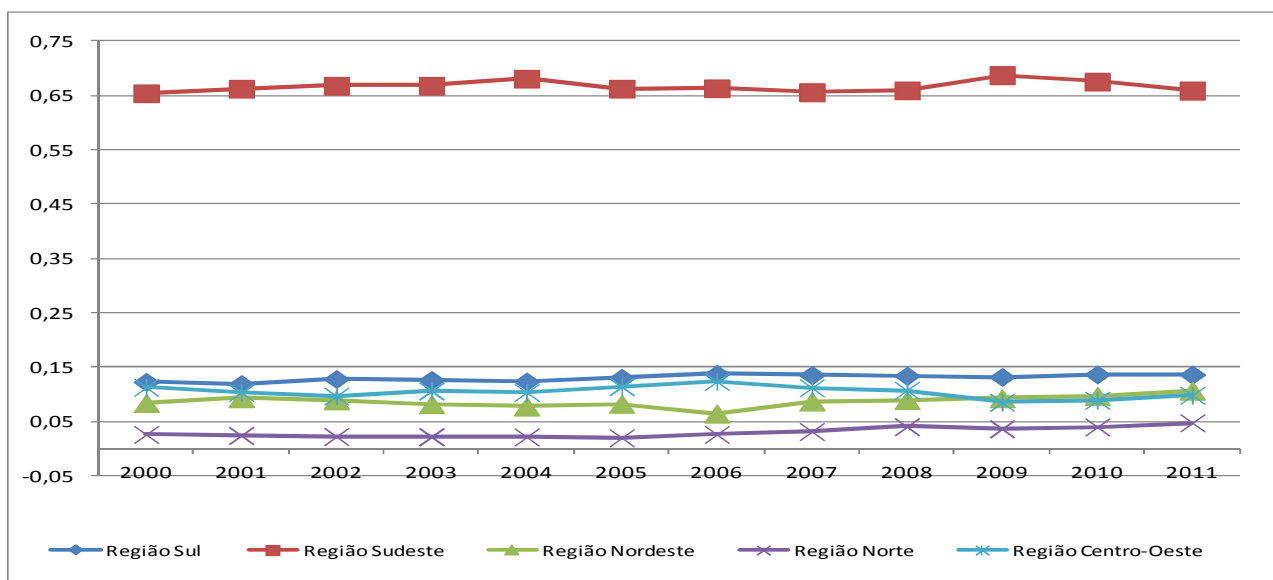

Fonte: Elaboração própria a partir dos dados do Estban-BCB, 2011.

Em resumo, pode-se concluir que há um grande espaço a ser preenchido pelas ações mercadológicas das instituições bancárias no tocante a oferta de crédito para as regiões menos desenvolvidas. As evidências mostradas sugerem que como os bancos possuem uma quantidade maior de informação da região mais desenvolvida, onde concentram suas atividades de tesouraria, tendem a emprestar relativamente menos nas regiões menos desenvolvidas, reduzindo o potencial de desenvolvimento econômico destas regiões. Em outras palavras, a concentração bancária implica que a atuação da firma bancária se dá conforme a percepção de oportunidades das regiões mais desenvolvidas, perpetuando as desigualdades econômicas e limitando a funcionalidade do sistema bancário para reduzir a desigualdade regional. 


\section{Determinantes da oferta de crédito à pessoa jurídica por região nos anos 2000- 2011}

O objetivo desta seção é avançar na discussão sobre a desigualdade regional de crédito no Brasil nos anos 2000s apresentando um modelo empírico dos determinantes do crédito regional a pessoas jurídicas. A especificação genérica do modelo a ser testado pode ser expressa como:

$$
C_{i t}=c+\beta_{1} X_{i t}+\varepsilon_{i t}
$$

em que a variável dependente $C$ - média anual do volume de operações de crédito da pessoa jurídica - é explicada por um termo $c$, constante, e um vetor $X$ que representa o conjunto de variáveis explicativas a serem testadas e $\varepsilon$ é o termo que representa o erro da estimativa. O subscrito $i$ indica a região geográfica e $t$, o tempo.

A discussão teórica apresentada nas seções 1 e 2, sobre o papel dos bancos em economias monetárias e a teoria da preferência pela liquidez dos bancos a nível regional, fornece um guia para a escolha do conjunto apropriado de variáveis para se estimar os determinantes da oferta de crédito para as pessoas jurídicas nas regiões do Brasil nos anos de 2000 a 2011. A base desta teoria é o argumento de que bancos interagem com as firmas ofertando recursos conforme sua percepção de ganhos monetários. Esta percepção envolve basicamente dois condicionantes: de um lado, as expectativas e grau de confiança associados aos ganhos futuros e, de outro, avaliações sobre aplicações alternativas dos recursos.

O conceito de preferência pela liquidez atende ao primeiro condicionante, e deve ser traduzido em uma medida que expresse o quanto a instituição bancária está disposta a comprometer seus ativos líquidos em operações de empréstimo. Supõe-se que, à medida que a percepção sobre o futuro seja mais pessimista e o grau de confiança sobre as expectativas mais incerto, o comportamento racional dos bancos é aumentar sua preferência pela liquidez, ou seja, mover-se para aplicações mais líquidas e de menor risco. Expectativas mais otimistas sobre o futuro e com menor grau de incerteza, ou seja, mais confiança, deve mover instituições bancárias na direção de ofertar mais crédito ${ }^{15}$.

A decisão sobre o montante de recursos disponível para empréstimo depende também da alocação alternativa dos recursos. Neste sentido, a avaliação sobre aplicações alternativas deve levar em conta a taxa básica de juros da economia, pois é ela a referência para empréstimos entre instituições financeiras e para a remuneração de títulos públicos ${ }^{16}$.

(15) De acordo com Cavalcante (2006), uma medida de preferência pela liquidez dos bancos deve captar o quanto o banco decide disponibilizar de seus ativos de maior prazo em relação a suas obrigações mais imediatas. Esse indicador é amplamente utilizado nos modelos que tratam dos determinantes do crédito.

(16) Esta variável foi utilizada por Fucidji e Mendonça (2009). 
Além de variáveis que captam o princípio básico que move a motivação das instituições bancárias para ofertar crédito às empresas, cabe considerar também fatores especifícos do desenvolvimento do sistema bancário. Neste sentido, assumese que a oferta de crédito depende também do grau de desenvolvimento do sistema bancário nas regiões, que pode ser avaliado, dentre outras medidas, pelo volume de depósitos à vista. Esta medida estaria expressando não só a disponibilidade de serviços bancários, mas também o grau de confiança do público nas instituições bancárias ${ }^{17}$.

A elevada desigualdade na distribuição do crédito no país implica assumir, conforme o princípio da causação circular cumulativa, que regiões mais desenvolvidas economicamente devem receber maior volume de crédito justamente por serem mais desenvolvidas ${ }^{18}$. Entre os setores da região central que gozam de economias de escala dinâmicas está o setor financeiro. $\mathrm{O}$ fato de que as instituições financeiras tendem a ter sede nas regiões centrais implica um afastamento das fontes de financiamento de investimento para as empresas em regiões periféricas. $\mathrm{Na}$ medida em que isto se verifica, mais se acentua a desigualdade econômica.

Nesse sentido, uma medida que expresse a desigualdade na distribuição do crédito deve ser incluída no modelo. A fim de complementar o conjunto de variáveis a serem testadas, recorreu-se à literatura recente sobre oferta de crédito regional, incluindo-se outras variáveis. O modelo elaborado utiliza dados em painel a nível regional $^{19}$. Uma aproximação sobre as variáveis a serem testadas no modelo empírico de oferta de crédito às empresas, de acordo com os argumentos acima, pode ser escrita como $^{20}$ :

$$
C_{i t}=c+\beta_{1} P L_{i t}+\beta_{2} \text { Selic }_{t}+\beta_{3} D V_{i t}+\beta_{4} I R C_{i t}+\beta_{5} D P P_{i t}+\beta_{6} A T P I B_{i t}+\beta_{7} C P F_{i t}+f_{i}+
$$

Na equação empírica; $C$ é o volume de operações de crédito à pessoa jurídica $^{21}, P L$ é a preferência pela liquidez ${ }^{22}$, Selic é a taxa básica de juros da economia, $D V$ é o volume depósitos à vista do setor privado, IRC é o índice regional de crédito, DPP é a razão Depósitos a prazo sobre Passivo, ATPIB é a razão Ativo

(17) Ver exemplos em Cavalcante, Crocco e Jayme Jr. (2006), Romero e Jayme Jr. (2009), Fucidji e Mendonça (2009).

(18) A teoria da causação circular cumulativa salienta as vantagens competitivas das regiões mais desenvolvidas. O crescimento em si permite às economias dinâmicas de escala serem colhidas em uma variedade de contextos, levando a um crescimento mais rápido da produtividade, o que torna ainda mais difícil para outras regiões competir.

(19) Ver, por exemplo, Cavalcante, Crocco e Jayme Jr. (2006), Romero e Jayme Jr. (2009), Fucidji e Mendonça (2009), Freitas e De Paula (2010), Crocco (2010), Crocco et al. (2011), entre outros.

(20) O Apêndice A descreve todas as variáveis que foram utilizadas.

(21) A descrição da base de dados se encontra no Apêndice A.

(22) Conforme Crocco (2010, ) a preferência pela liquidez é a razão entre os depósitos à vista e as operações totais de crédito, ou seja, o quociente da variável mais líquida em poder do banco contra a variável menos líquida. 
total sobre PIB e CPF é o crédito à pessoa física. No caso de $D P P$, o objetivo de sua inclusão foi avaliar a hipótese de que uma maior proporção de depósitos a prazo indica maior disponibilidade de crédito. No caso de $A T P I B$, o objetivo foi testar se uma alta participação do ativo dos bancos no PIB, indicando uma maior consolidação do sistema financeiro na estrutura produtiva, implica uma maior disponibilidade de crédito $^{23}$. Um diferencial no modelo é a inserção da variável crédito à pessoa física, $C P F$. O objetivo desta variável é testar se o crédito à pessoa física concorre com o crédito destinado à pessoa jurídica. Vale lembrar que a partir de 2003 foi criado o crédito consignado, modalidade que torna praticamente nulo o risco de inadimplencia nesta modalidade de crédito. Dada a forte demanda pelo crédito consignado, o crédito à pessoa física cresceu bastante a partir de 2003, podendo concorrer com o crédito a firmas. Por fim, $f i$ é o efeito específico de cada unidade federativa e $\varepsilon$ é o termo que representa o erro da estimativa.

\subsection{Prodecimentos metodológicos}

Para construir as variáveis do modelo econométrico (ver descrição da base de dados e das variáveis no Apêndice A) foi necessário compatibilizar as informações de oferta de crédito por estado, disponíveis no Sistema Gerenciador de Séries Temporais - SGS - do Banco Central do Brasil, com as informações do Estban, disponíveis por municípios. Assim, agruparam-se os dados de municípios por estados ${ }^{24}$. As séries referentes ao PIB das unidades federativas e da taxa de juros Selic foram retiradas do Ipeadata. $\mathrm{O}$ banco de dados construído para gerar o painel de dados para a análise empírica abrange o período 2000-2011, totalizando no máximo 324 observações para cada uma das variáveis selecionadas.

Para estimação dos coeficientes, são utilizados dois métodos: método dos mínimos quadrados ordinários (OLS) e o método generalizado dos momentos (GMM). A justificativa para o uso de ambos os métodos é de dar maior robustez aos resultados encontrados. Uma das razões para a utilização do GMM deve-se ao fato de que as estimativas em OLS (apresentadas no Apêndice B) normalmente apresentam problemas de autocorrelação serial e heterocedasticidade ${ }^{25}$. Sendo assim, com o GMM, os estimadores ganham consistência para a regressão (Hansen,

(23) Crocco et al. (2011, p. 298), seguindo argumentos de Dow e Fuentes (2006), utilizam esta razão $(A T P I B)$ para medir a relação entre desenvolvimento do sistema financeiro e crescimento econômico de uma região.

(24) Deu-se um tratamento especial à região Centro-Oeste. Essa região abriga a capital do país, Brasília, onde estão as sedes dos dois maiores bancos públicos do país (Banco do Brasil e Caixa Econômica Federal). Isto implica que todas as operações bancárias relacionadas à administração federal estão concentradas nesta cidade. Assim, os balancetes das agências bancárias destes bancos em Brasília apresentam resultados que estão influenciados não apenas por fatores econômicos, mas principalmente pelo fator político. Dessa forma, na análise que se segue os dados relativos à região Centro-Oeste serão apresentados sem a cidade de Brasília.

(25) Como apontado por Wooldridge (2001), "to obtain a more efficient estimator than two-stage least squares (or ordinary least squares), one must have overriding restrictions." 
1982), elevando a robustez da análise. Além disso, as variáveis instrumentais escolhidas (Tabela C2 no Apêndice C) necessitam ser defasadas em pelo menos um período, de forma a ajudar a predizer as correspondentes variáveis contemporâneas, ou seja, busca-se, dessa forma, evitar a questão da endogeneidade nas estimações das variáveis ${ }^{26}$.

Com objetivo de se verificar a relevância das variáveis instrumentais do modelo foram aplicados testes de restrições às sobreidentificações (teste de Sargan, no final da tabela 1), como proposto por Arellano (2003). Nesse contexto, com a intenção de não gerar resultados espúrios, foi realizado o teste de raiz unitária (resultados no Apêndice $\mathrm{C}$, Tabela $\mathrm{C} 1$ ), que indicou a presença de não estacionariedade em todas as séries. Uma vez que as séries são todas I(1), este estudo faz a estimativa em primeira diferença, pelo método GMM - dinâmico com dados em painel, com o objetivo de eliminar os efeitos não observados nas regressões ${ }^{27}$. Além disso, foi aplicado o logaritmo neperiano $(L n)$ das variáveis para minimizar a variância.

Tendo em vista a natureza dos dados, a forma mais robusta de se proceder com a estimação da equação empírica é por meio de um painel de efeito fixo. A principal vantagem desse método é a sua habilidade no tratamento de efeitos não observados e variáveis omissas, ou seja, qualquer variável omissa que seja constante ao longo do tempo não afeta a consistência do estimador, mesmo que a variável omissa seja correlacionada com as variáveis explicativas do modelo. Nesse contexto, a intuição que emerge é que todos os efeitos não observados serão capturados pelo intercepto específico de cada região.

\subsection{Resultados}

Os resultados na Tabela 1, utilizando o método GMM, mostram que os sinais dos coeficientes das variáveis explicativas estão em conformidade com os valores esperados, excetuando o quociente Ativo/PIB para a região Sudeste e o IRC para a região Centro-Oeste que apresentaram sinais contrários ao esperado. No entanto, os resultados contraditórios aos sinais esperados não são significantes.

A avaliação da estimação dos determinantes do crédito para pessoa jurídica a nível Brasil permite concluir que a variável com maior impacto negativo para explicar o comportamento do crédito bancário às empresas foi a preferência pela liquidez (PL) em todas as regiões, superando o coeficiente da variável Selic. Este resultado chama a atenção em especial para a região Sudeste, a mais rica do país,

(26) Esse procedimento de escolha das variáveis instrumentais segue Johnston (1984).

(27) Conforme Arellano e Bond (1991), uma vantagem deste método em relação aos demais, por exemplo, Mínimos Quadrados Ordinários (OLS) e Mínimos Quadrados Generalizados - Generalized Least Squares (GLS) , é que as estimações são confiáveis mesmo no caso de haver variáveis omitidas. 
Desigualdade na oferta de crédito regional a pessoas jurídicas: uma análise em painel...

reforçando a ideia de que o impacto do crédito às empresas é guiado principalmente pela avaliação da percepção das instituições bancárias quanto ao retorno esperado. Além disso, como mostrado na discussão teórica, esta variável apresentou menor resultado em relação às demais regiões. Este resultado corrobora o posicionamento pós-keynesiano de que os bancos possuem um estoque informacional mais apurado na região mais desenvolvida que faz aumentar a confiança que depositam no futuro dessa região econômica como também nos tomadores de empréstimo. Nesse contexto, o Sudeste, por apresentar uma estrutura produtiva mais diferenciada, tende a apresentar menor preferência pela liquidez da firma bancária.

Tabela 1

Resultados das estimações GMM para o Brasil e regiões - (2000-2011)

\begin{tabular}{|c|c|c|c|c|c|c|}
\hline \multicolumn{7}{|c|}{ Variáveis Explicativas } \\
\hline & Brasil & Sudeste & Sul & Nordeste & Norte & C Oeste \\
\hline \multirow[t]{3}{*}{ Constante } & $11,67831^{*}$ & $14,20627 *$ & $13,5096^{*}$ & $8,03733^{*}$ & $12,35402 *$ & $24,03333 *$ \\
\hline & $(1,733022)$ & $(0,914474)$ & $(1,019141)$ & $(2,651737)$ & $(2,570817)$ & $(3,265545)$ \\
\hline & {$[6,738696]$} & {$[15,53491]$} & {$[13,25587]$} & {$[3,030969]$} & {$[4,805481]$} & {$[7,359669]$} \\
\hline \multirow[t]{3}{*}{ LN PL 400410 160(Pref liquidez) } & $-0,743124 *$ & $-0,592715^{*}$ & $-0,920922 *$ & $-0,745228 *$ & $-0,798757 *$ & $-1,306087 *$ \\
\hline & $(0,102326)$ & $(0,073135)$ & $(0,166035)$ & $(0,117396)$ & $(0,130218)$ & $(0,115362)$ \\
\hline & {$[-7,262338]$} & {$[-8,104377]$} & {$[-5,546550]$} & {$[-6,347976]$} & {$[-6,133998]$} & {$[-11,32167]$} \\
\hline \multirow[t]{3}{*}{ LN SELIC } & $-0,153331 * *$ & $-0,209847 * *$ & $-0,184166^{*}$ & $-0,293273^{*}$ & $-0,383533^{*}$ & $-0,218557 * * *$ \\
\hline & $(0,072231)$ & $(0,093607)$ & $(0,055182)$ & $(0,100472)$ & $(0,112409)$ & $(0,106771)$ \\
\hline & {$[-2,122788]$} & {$[-2,241781]$} & {$[-3,337422]$} & {$[-2,918956]$} & {$[-3,411938]$} & {$[-2,046961]$} \\
\hline \multirow[t]{3}{*}{ LN DV 412(Dep à Vista) } & $0,754636^{*}$ & $0,407998 *$ & $0,531859^{*}$ & $1,405651 *$ & $0,886929 *$ & $0,466572 * * *$ \\
\hline & $(0,092880)$ & $(0,086024)$ & $(0,140198)$ & $(0,099027)$ & $(0,157200)$ & $(0,271253)$ \\
\hline & {$[8,124846]$} & {$[4,742862]$} & {$[3,793637]$} & {$[14,19459]$} & {$[5,642041]$} & {$[1,720061]$} \\
\hline \multirow[t]{3}{*}{ LN IRC(Índ Regional Crédito) } & & 0,048524 & 0,275581 & $0,519960^{*}$ & $0,713522 *$ & $-0,325118$ \\
\hline & & $(0,236190)$ & $(0,170769)$ & $(0,129983)$ & $(0,192000)$ & $(0,486463)$ \\
\hline & & {$[0,205443]$} & {$[1,613770]$} & {$[4,000208]$} & {$[3,716256]$} & {$[-0,668331]$} \\
\hline \multirow[t]{3}{*}{ LN DP P(Dep à Prazo/Passivo) } & $0,195114^{*}$ & 0,010912 & $0,062823 *$ & $0,246977 *$ & $0,138851 *$ & $0,208975^{* *}$ \\
\hline & $(0,024631)$ & $(0,128816)$ & $(0,023669)$ & $(0,021803)$ & $(0,044376)$ & $(0,087950)$ \\
\hline & {$[7,921653]$} & {$[0,084713]$} & {$[2,654255]$} & {$[11,32779]$} & {$[3,128963]$} & {$[2,376067]$} \\
\hline \multirow[t]{3}{*}{ LN AT PIB(Ativo/PIB) } & $0,149454 *$ & $-0,053998$ & $0,030192 *$ & $0,170540 *$ & $0,106228 * *$ & $0,110871 * *$ \\
\hline & $(0,022311)$ & $(0,120710)$ & $(0,009212)$ & $(0,021803)$ & $(0,043343)$ & $(0,051058)$ \\
\hline & {$[6,698722]$} & {$[-0,447334]$} & {$[3,277493]$} & {$[7,821718]$} & {$[2,450875]$} & {$[2,171471]$} \\
\hline \multirow[t]{3}{*}{ LN CPF(Crédito Pessoa Física) } & $-0,250351^{*}$ & $-0,002137$ & $-0,116968$ & $-0,651370^{*}$ & $-0,399615^{*}$ & $-0,572439 *$ \\
\hline & $(0,087216)$ & $(0,048355)$ & $(0,169054)$ & $(0,114999)$ & $(0,076728)$ & $(0,165197)$ \\
\hline & {$[-2,870456]$} & {$[-0,044196]$} & {$[-0,691896]$} & {$[-5,664140]$} & {$[-5,208195]$} & {$[-3,465180]$} \\
\hline Adj. $R^{2}$ & 0,998193 & 0,999014 & 0,989701 & 0,996992 & 0,995558 & 0,992197 \\
\hline número de instrumentos & 57 & 18 & 27 & 35 & 30 & 36 \\
\hline número de observações & 243 & 32 & 19 & 54 & 56 & 20 \\
\hline testes de Sargan & 57.925 & 10.581 & 12.870 & 23.824 & 19.392 & 9.237 \\
\hline (valor-p) & 0,206 & 0,391 & 0,845 & 0,640 & 0,620 & 0,682 \\
\hline
\end{tabular}

Notas: Níveis de significância $(*)$ denota 0,$01 ;(* *)$ denota 0,$05 ;(* *)$ denota 0,10 . Erro padrão entre parênteses e $\mathrm{t}$ - statistic em colchetes.

Fonte: Elaboração dos autores.

Pode-se dizer também que tal resultado reforça a hipótese do paradoxo financeiro da eficência social, pois ao indicar que bancos decidem emprestar guiados principalmente por sua percepção de ganhos em função das oportunidades alternativas de alocação de recursos, implica afirmar que preferem reter ativos mais líquidos nas regiões menos desenvolvidas. Desta forma impõem um mecanismo perverso na expansão da demanda efetiva via ruptura de expansão de novos 
processos de financiamento bancário. Quando isto ocorre, não serão contratados novos meios de produção e, por fim, será comprometida a geração de novas rodadas de remunerações dos fatores de capital investidos, levando à ruptura do processo de crescimento econômico.

A variável Selic, significativa em todas as regiões, foi a que apresentou o segundo maior impacto ao contrair a oferta de crédito à pessoa jurídica, mostrando grande sensibilidade do crédito empresarial às decisões de política monetária emandas pelo Banco Central.

Quanto aos depósitos à vista, essa variável foi significativa em todas as regiões e o seu resultado demonstra que quanto maior o volume de depósitos, maior tende a ser o volume de crédito disponível. Assim, as instituições bancárias, reforçando o argumento pós-keynesiano da oferta de moeda endógena, fornecem poder de compra novo por intermédio da criação de moeda escritural.

O coeficiente do IRC foi significativo apenas nas regiões Sul, Nordeste e Norte, o que, em parte, não ratifica o argumento dado pela teoria. A variável depósitos a prazo sobre o Passivo $(D P P)$, apresenta uma relação positiva com o volume de operações de crédito para pessoa jurídica, porém seu coeficiente é relativamente baixo em todas as especificações. Dessa forma, a indicação sugere que os depósitos a prazo não são utilizáveis de forma robusta como contrapartida de funding para o alongamento dos prazos dos empréstimos sendo, portanto, uma fonte pouco explorada de recursos de origem privada no circuito financeiro. Esta variável não foi significativa na região Sudeste.

Quanto à variável ativo total sobre o PIB (ATPIB), encontrou-se o sinal esperado excetuando as regiões Sudeste e Norte que apresentaram sinais negativos, porém não significativos. De uma forma geral, uma maior participação do ativo dos bancos no total de riqueza gerada poderia implicar uma maior disponibilidade de crédito. Apesar de significativos, os coeficientes encontrados foram relativamente baixos. Nesse contexto, ratifica-se a desconstrução da tese voltada para o elo de ligação entre o tamanho do sistema bancário medido por seus ativos e sua capacidade de gerar crédito para explicar a dinâmica da oferta de recursos à pessoa jurídica.

A estratégia na construção do modelo de usar a variável crédito pessoa física $(C P F)$ foi capturar se a mesma interferia nas disposições das instituições financeiras em prover crédito às empresas. Ao se mostrar estatisticamente significante, a variável vem corroborar a ideia de que esse tipo de crédito acabou por concorrer diretamente na oferta de crédito empresarial. Dessa forma intui-se que os bancos, ao previlegiarem o crédito à pessoa física em detrimento ao crédito à pessoa jurídica, estão em busca de maior rentabilidade para suas aplicações visto que o crédito à pessoa física possui taxas mais elevadas que a do setor empresarial. Vale observar que esta variável não foi significativa para as regiões Sudeste e Sul, o que sugere que como a atividade bancária nestas regiões é mais desenvolvida, a perspectiva de 
crescimento da renda e, portanto, de expansão da demanda de crédito pessoal, não foi relativamente mais atraente como aplicação para os bancos, como nas outras regiões mais pobres.

Deve-se ressaltar que a importância relativa desta variável nas regiões menos desenvolvidas pode ser atribuída à inovação institucional relativa à criação do crédito consignado com desconto em folha de pagamento em dezembro de 2003. Pode-se sugerir que as instituições das regiões mais pobres apostaram neste mercado com mais intensidade justamente por ter seus riscos quase nulos devido à garantia dos recebíveis descontados na fonte geradora do fluxo financeiro. Diante de tal fato, expõe-se que a variável $C P F$ concorreu diretamente com o crédito às empresas devido à maior preferência pela rentabilidade e menor risco por parte das instituições financeiras nas regiões mais pobres. No entanto, para um modelo ideal de funcionalidade financeira e de mais um braço de sustentação da tese de eficiência social que o sistema bancário poderia promover, essa variável deveria ser complementar (com sinal positivo) ao crédito empresarial ao dar corpo de sustentação às demandas de novas rodadas de produto, podendo permitir um círculo virtuso da atividade econômica regional.

Uma avaliação geral da estimação dos determinantes do crédito para pessoa jurídica para as regiões mostrou que a preferência pela liquidez, um indicador do grau de racionamento de crédito, é maior em regiões menos desenvolvidas, ratificando um comportamento que identificamos como o paradoxo financeiro da eficiência social. Desta forma, bancos, em busca de maior rentabilidade, reforçam desigualdades na geração de renda e produto ao não atenderem demandas de regiões menos desenvolvidas. Para contrabalançar o processo perverso que o paradoxo financeiro da eficiência social pode causar, políticas públicas via complemento de atuação dos bancos de desenvolvimento regional paracem ser inevitáveis.

Nesse contexto, Crocco (2003) levanta uma série de instrumentos e instituições voltados para a cobertura dessa lacuna a fim de corrigir as assimetrias do livre mercado. Boa parte delas está centrada apenas na concessão de linhas de financiamentos especiais para regiões atrasadas como os fundos constitucionais de financiamento e fundos fiscais de investimentos. Outros exemplos se inserem nos diversos programas de desenvolvimento regional de diversas agências de fomento, tais como o Banco Nacional de Desenvolvimento Econômico e Social (BNDES), Companhia de Desenvolvimento do Vale do São Francisco (Codevasf), Departamento de Obras Contra a Seca (DNOCS), Superintendência da Zona Franca de Manaus (Suframa), dentre outras.

\section{Consideração final}

O objetivo deste trabalho foi, apoiado em um modelo econométrico, identificar os determinantes do crédito a pessoas jurídicas no Brasil e regiões. Com 
os resultados do modelo, concluímos que a variável mais importante em termos de impacto na oferta de crédito é a preferência pela liquidez, desmitificando a própria taxa básica de juros como variável proeminente. Nesse contexto, a preferência pela liquidez é o fio condutor da orientação da firma bancária na alocação de seus recursos com base nas avaliações de suas percepções quanto aos retornos esperados.

Dada essa constatação, identificamos que as regiões periféricas vivem o que denominamos de um paradoxo financeiro da eficiência social que pode perpetuar a estagnação econômica frente às dinâmicas das regiões mais desenvolvidas. No nosso teste econométrico, uma indicação adicional da existência do paradoxo pode ser vista no comportamento do crédito à pessoa física, que se expandiu em grande medida devido ao crédito consignado a partir de 2004, que concorreu com o crédito a firmas nas regiões periféricas. Nesse contexto, políticas públicas, por intermédio da atuação de bancos públicos regionais, podem ser utilizadas como mecanismo de complemento do hiato de recursos financeiros destinados ao financiamento das diversas demandas efetivas regionais e, consequentemente, seu crescimento econômico.

\section{Referências bibliográficas}

AMADO, A. Disparate regional development in Brazil: a monetary production approach. Ashgate, 1997.

ARELLANO, M. Panel data econometrics. Oxford: Oxford University Press, 2003.

; BOND, S. Some tests of specification for panel data: Monte Carlo evidence and an application to employment equations. Review of Economic Studies, 58, p. 277-297, 1991.

CAVAlCANTE, A. T. M.; CROCCO, M; BRITO, M. L. A. Impactos macroeconômicos na variação regional da oferta de crédito. Análise Econômica, Porto Alegre, ano 25, n. 47, p. 85-120, mar. 2007.

Financiamento e desenvolvimento local: um estudo sobre arranjos produtivos. Master's thesis, Centro de Desenvolvimento e Planejamento Regional, Faculdade de Ciências Econômicas, Universidade Federal de Minas Gerais, Belo Horizonte, 2006.

;

; JAYME JR., F. G. Preferência pela liquidez, sistema bancário e disponibilidade de crédito regional. In: CROCCO, Marco; JAYME JR., Frederico G. Moeda e território: uma interpretação da dinâmica regional brasileira. Belo Horizonte: Autentica, 2006. p. 295-315.

CHICK, V. The evolution of the banking system and the theory of saving, investment and interest. Economic et Sociétes, 1986. (Ahiers de I'Ismea, Série Monnaire et production, n. 3). 
CROCCO, M. A. Financiamento do desenvolvimento regional no Brasil: diagnósticos e propostas. In: SICSÚ, J.; OREIRO, J. L.; PAULA, L. F. (Org.). Agenda Brasil: políticas econômicas para o crescimento com estabilidade de preços. Ed. Konrad-Adenauer-Stiftung, 2003.

Moeda e desenvolvimento regional e urbano: uma leitura Keynesiana e sua aplicação ao caso brasileiro. Tese (Professor Titular)-Cedeplar, abr. 2010.

; NOGUEIRA, M.; ANDRADE, C. M. C.; DINIZ. G. F. C. O estudo do gap regional de crédito e seus determinantes, sob uma ótica pós-keynesiana. Economia, v. 12. n. 2, p. 281-307, maio/ago. 2011.

DE PAULA, L. F. R.; ALVES JR., A. J. Comportamento dos bancos, percepção de risco e margem de segurança no ciclo minksiano, Análise Econômica, ano 21, n. 39, mar. 2003.

DOW, S. C. The regional composition of the money multiplier process. Scottisch Journal of Political Economy, v. 29, n. 1, 1982.

. Financial markets and regional economic development: the Canadian experience. Aldershot: Avebury, 1990.

; FUENTES, C. J. R. Um "survey” da literatura de finanças regionais. In: CROCCO, M. A. JAYME JR., F. G. (Ed.). Moeda e território: uma interpretação da dinâmica regional brasileira. Belo Horizonte: Autêntica, 2006.

DYMSKI, G. Exclusão financeira: a transformação global do Core Banking, um estudo de caso sobre o Brasil. In: DE PAULA, L. F.; OREIRO, J. (Org.). Sistema financeiro: uma análise do setor bancário brasileiro. 2007.

FERREIRA JR., R. R.; SORGATO, L. A. A.; ROSÁRIO, F. J. P. Estratégias de inclusão financeira produtiva em regiões periféricas: uma proposta para o Nordeste. In: ENCONTRO DE ECONOMIA BAHIANA, 7, set. 2012.

FREITAS, A. P. G.; PAULA, L. F. R. Concentração regional do crédito e consolidação bancária no Brasil: uma análise pós-Real. EconomiA, Brasília, v.11, n. 1 , p. 97-123, jan./abr. 2010.

FUCIDJI, J. R.; MENDONÇA, D. P. Determinantes do crédito bancário: uma análise com dados em painel para as maiores instituições. Análise Econômica, Porto Alegre, v. 27 , n. 52 , set. 2009 .

FURTADO, C. Subdesenvolvimento e estagnação na América Latina. Rio de Janeiro: Civilização Brasileira, 1966.

Análise do modelo brasileiro. Rio de Janeiro: Civilização Brasileira,

1972.

GREENE, W. Econometric analysis. $3^{\text {rd }}$ ed. Prentice Hall, 1997. 
HANSEN, L. P. Large sample properties of generalized methods of moments estimators. Econometrica, v. 50, n. 4, p. 1029-1054, 1982.

JOHNSTON, J. Econometric methods. McGraw-Hill, 1984.

KEYNES, J. M. (1930). The treatise on money; the pure theory of money Collect Writings. Edited by D. E. Maggridge and E. Johnson. Macmillam for the Royal Econommic Society, 1971. v. V.

. The general theory of employment, interest and money. New York: Hartcourt Brace and World, 1936.

LEVINE, R. Finance and growth: theory and evidence. National Bureau of Economic Research, 2004. (NBER Working Papers Series, 0766). Disponível em: http://www.nber.org/papers/w10766.

MENEZES, M.; CROCCO, M.; SANCHES, E.; AMADO, A. Sistema financeiro e desenvolvimento regional: notas exploratórias. In: SISTEMA financeiro, uma análise do setor bancário brasileiro. Campus, 2006. p. 285-305.

MINSKY, H. P. The financial-instability hypothesis: capitalist processes and the behavior of the economy. In: KINDLEBERGER; LAFFARGUE (Ed.). Financial crises. Cambridge University Press, 1982.

. Stabilizing an unstable economy. New Haven: Yale University Press, 1986.

MYRDAL, Gunnar. Teoria econômica e regiões subdesenvolvidas. Rio de Janeiro: Saga, 1968.

NOGUEIRA, M.; CROCCO, M.; FIGUEIREDO, A. T.; DINIZ, G. Financial hierarchy and banking strategies: a regional analysis for the Brazilian case. Cambridge Journal of Economics, Jul. 2014.

RODRÍGUEZ-FUENTES, C. J. Credit availability and regional development. In: PROCEEDINGS OF THE EUROPEAN REGIONAL SCIENCE ASSOCIATION, 36, European Congress, Zurich, Aug. 1996.

ROMERO, J. P.; JAYME JR., F. G. Crédito, preferência pela liquidez e desenvolvimento regional: o papel dos bancos públicos e privados no sistema financeiro brasileiro (2001-2006). In: ENCONTRO NACIONAL DE ECONOMIA POLÍTICA, 14, Enep, 2009, São Paulo. Anais... Disponível em: http://www.academia.edu/396646/Cr\%C3\%A9dito_Prefer\%C3\%AAncia_Pela_Liq uidez_e_Desenvolvimento_Regional_O_Papel_dos_Bancos_P\%C3\%BAblicos_e_ Privados_no_Sistema_Financeiro_Brasileiro. Acesso em: 13 nov. 2014.

STIGLITZ, J.; WEISS, A. Credit rationing in markets with imperfect information. American Economic Review, v.71, n. 3, Jun. 1981. 
STUDART, R. Financiamento do desenvolvimento. In. GIAMBIAGI, F.et al. (Org.). Economia brasileira contemporânea: 1945-2004. Rio de Janeiro: Elsevier, 2005.

VASCONCELOS, M. R.; FUCIDJI, J. R.; SCORZAFAVE, L. G.; ASSIS, D. L. O todo e as partes: uma análise da desigualdade de crédito entre os estados brasileiros e os determinantes do crédito bancário com aplicação de dados em painel. Economia e Sociedade, Campinas, v.13, n.1 (22), p. 123-149, jan./jun.2004.

WOOLDRIDGE, J. M. Applications of generalized method of moments estimation. Journal of Economic Perspectives, v. 15, n. 4, p. 87-100, 2001.

. Econometric analysis of cross section and panel data. MIT Press, 2002.

\section{Referências das fontes de dados}

BCB - Banco Central do Brasil. Estatísticas bancárias por municípios - Estban. Disponível em: http://www4.bcb.gov.br/fis/cosif/estban.asp. Acesso em: 2 jan. 2015.

BCB - Banco Central do Brasil. Sistema Gerenciador de Séries Temporais SGS Economia regional. Disponível em: https://www3.bcb.gov.br/sgspub/localizarseries/localizarSeries.do?method=prepara rTelaLocalizarSeries. Acesso em: 2 jan. 2015.

IPEA - Instituto de Pesquisa Econômica Aplicada. Disponível em: http://www.ipeadata.gov.br/. Acesso em: 15 jan. 2015. 


\section{Apêndice A}

\section{Descrição da base de dados}

A base de dados Estatísticas Bancárias por Municípios - Estban, disponível no Banco Central do Brasil, disponibiliza dados financeiros apresentados em 83 contas. Os dados estão disponíveis a preços correntes. Os dados foram tabulados e somados por Unidades Federativas. Foram utilizadas as médias anuais dos dados. Para construção das variáveis utilizadas no modelo foram utilizadas as seguintes contas:

1) Operações de crédito (160)

2) Total do Ativo (399)

3) Depósitos à vista do governo ( 400)

4) Depósitos à vista do setor privado (412)

5) Depósitos a prazo (432)

6) Total do Passivo (899)

Outra base de dados utilizada foi o Sistema Gerenciador de Séries Temporais - SGS do Banco Central. Dessa base de dados foram retirados os dados de crédito referentes à economia regional, que só estão disponíveis mensalmente por unidade federativa, a preços correntes. Foram utilizadas as médias anuais dos dados de crédito disponíveis nas seguintes séries:

7) Saldo das operações de crédito - pessoa física

8) Saldo das operações de crédito - pessoa jurídica

9) Saldo das operações de crédito - total

As séries referentes ao PIB das unidades federativas e da taxa de juros Selic foram retidas do Ipeadata. Foram utilizadas as seguintes séries:

10) PIB estadual a preços correntes

11) PIB estadual a preços constantes do ano de 2000 - Deflacionado pelo deflator implícito do PIB nacional.

12) Taxa de juros Over - Selic

\section{Descrição das variáveis utilizadas no modelo:}

Preferência pela liquidez: $\ln \{[($ Depósitos à vista do governo (400) + Depósitos à vista do setor privado (410) / Operações de crédito(160) ]*100\}

Selic: $\ln ($ Taxa de juros Over - Selic) em percentual 
Desigualdade na oferta de crédito regional a pessoas jurídicas: uma análise em painel...

Depósitos à vista do setor privado: $\ln$ (Depósitos à vista do setor privado (412)

Índice Regional de Crédito: $\ln \{[($ Crédito do estado/total crédito Brasil)/(PIB do estado/PIB Brasil)]*100\}

Depósitos a prazo sobre o total do passivo: $\ln [$ (Depósitos a prazo (432) / total do Passivo (899)*100]

Total do Ativo sobre o PIB: $\ln [($ Total do Ativo (399)/ PIB a preços correntes)*100]

PIB: $\ln ($ PIB a preços constantes de 2000)

Crédito Pessoa Jurídica: Para a construção dessa série foi verificada qual a participação do crédito pessoa jurídica de cada unidade federativa no total do crédito nacional. Para fazer essa verificação foram utilizadas as séries do SGS 14029 e 14056. Para a construção da série no período de 2000 a 2003 foram utilizadas as mesmas participações do ano de 2004. Assim como nas demais séries, foi utilizado o $\ln$ dos valores.

Crédito Pessoa Física: Para a construção dessa série foi verificada qual a participação do crédito pessoa física de cada unidade federativa no total do crédito nacional. Para fazer essa verificação foram utilizadas as séries do SGS 14002 e 14056. Para a construção da série no período de 2000 a 2003 foram utilizadas as mesmas participações do ano de 2004. Assim como nas demais séries, foi utilizado o ln dos valores. 


\section{Apêndice B}

Resultados das estimações MQO para o Brasil e regiões - (2000-2011)

\begin{tabular}{|c|c|c|c|c|c|c|}
\hline \multicolumn{7}{|c|}{ Variáveis Explicativas } \\
\hline & Brasil & Sudeste & Sul & Nordeste & Norte & C Oeste \\
\hline \multirow[t]{3}{*}{ Constante } & $12,04255^{*}$ & $14,21827 *$ & $11,67635^{*}$ & $11,67287 *$ & $9,193519 *$ & $15,76355^{*}$ \\
\hline & $(0,594400)$ & $(-1,299108)$ & $(1,504271)$ & $(1,018791)$ & $(1,914567)$ & $(2,183136)$ \\
\hline & {$[20,26001]$} & {$[10.94465]$} & {$[7,762131]$} & {$[11,45758]$} & {$[4,801878]$} & {$[7,220602]$} \\
\hline \multirow[t]{3}{*}{ LN PL 400410 160(Pref liquidez) } & $-1,012001 *$ & $-0,723024 *$ & $-0,672289 *$ & $-1,213043^{*}$ & $-0,8477 *$ & $-1,341547 *$ \\
\hline & $(0,052207)$ & $(0.071614)$ & $(0,033787)$ & $(0,188377)$ & $(0,080960)$ & $(0,150529)$ \\
\hline & {$[-19,38420]$} & {$[-10.09608]$} & {$[-19,89798]$} & {$[-6,439453]$} & {$[-10,47058]$} & {$[-8,912195]$} \\
\hline \multirow[t]{3}{*}{ LN SELIC } & $-0,109884^{*}$ & $-0,316839^{*}$ & $-0,160183^{*}$ & $-0,201997^{*}$ & $-0,059286$ & $-0,136032 * *$ \\
\hline & $(0,033833)$ & $(0.060073)$ & $(0,033807)$ & $(0,065280)$ & $(0,092777)$ & $(0,059862)$ \\
\hline & {$[-3,247778]$} & {$[-5,274208]$} & {$[-4,738223]$} & {$[-3,094306]$} & {$[-0,639017]$} & {$[-2,272405]$} \\
\hline \multirow[t]{3}{*}{ LN DV 412(Dep à Vista) } & $0,601127^{*}$ & $0,513267 *$ & $0,422147 *$ & $0,82512 *$ & $0,828859 *$ & $1,329662 *$ \\
\hline & $(0,055001)$ & $(0.117069)$ & $(0,049760)$ & $(0,188399)$ & $(0,083107)$ & $(0,114329)$ \\
\hline & {$[10,92937]$} & {$[4.384305]$} & {$[8,483703]$} & {$[4,379631]$} & {$[9,973361]$} & {$[11,63016]$} \\
\hline \multirow[t]{3}{*}{ LN IRC(Índ Regional Crédito) } & & $0,283706^{*}$ & 0,101474 & 0,100325 & $0,527291 *$ & 0,25841 *** \\
\hline & & $(0.077220)$ & $(0,145530)$ & $(0,101355)$ & $(0,159962)$ & $(0,136632)$ \\
\hline & & {$[3.673993]$} & {$[0,697272]$} & {$[0,989837]$} & {$[3,296352]$} & {$[1,891281]$} \\
\hline \multirow[t]{3}{*}{ LN DP P(Dep à Prazo/Passivo) } & $0,076464^{*}$ & $-0,038551$ & $0,055806^{* * * *}$ & 0,007118 & $0,085807 *$ & $0,142371^{*}$ \\
\hline & $(0,013150)$ & $(0.042259)$ & $(0,032409)$ & $(0,046077)$ & $(0,027576)$ & $(0,040217)$ \\
\hline & {$[5,814566]$} & {$[-0,912254]$} & {$[1,721939]$} & {$[0,154473]$} & {$[3,111597]$} & {$[3,540034]$} \\
\hline \multirow[t]{3}{*}{ LN AT PIB(Ativo/PIB) } & $0,069390^{*}$ & $-0,063236$ & $0,05763^{*}$ & $-0,013327$ & $0,045821 * * *$ & 0,026182 \\
\hline & $(0,014098)$ & $(0.045518)$ & $(0,013313)$ & $(0,036534)$ & $(0,026453)$ & $(0,056789)$ \\
\hline & {$[4,921926]$} & {$[-1,389258]$} & {$[4,328866]$} & {$[-0,364786]$} & {$[1,732163]$} & {$[0,461041]$} \\
\hline \multirow[t]{3}{*}{ LN CPF(Crédito Pessoa Física) } & $-0,165152 *$ & $-0,106046$ & $0,078345^{*}$ & $-0,380637$ ** & $-0,249671 *$ & $-0,986231 *$ \\
\hline & $(0,045669)$ & $(0.080398)$ & $(0,014554)$ & $(0,148599)$ & $(0,059249)$ & $(0,122808)$ \\
\hline & {$[-3,616302]$} & {$[-1,319015]$} & {$[5,383204]$} & {$[-2,561504]$} & {$[-4,213962]$} & {$[-8,030642]$} \\
\hline F - statistic & 5893,824 & 6317,696 & 452,1949 & 974,7057 & 1210,237 & 573,5510 \\
\hline Adj. $\mathbf{R}^{2}$ & 0,99829 & 0,999256 & 0,991455 & 0,992727 & 0,994748 & 0,991858 \\
\hline
\end{tabular}

Notas: Níveis de significância $(*)$ denota 0,$01 ;(* *)$ denota 0,$05 ;(* * *)$ denota 0,10 Erro padrão ente parênteses e t - statistic em colchetes

Fonte: elaboração dos autores 


\section{Apêndice C}

1) Teste de raiz unitária para dados em painel

Tabela $\mathrm{C} 1$

Teste de raiz unitária nas séries

\begin{tabular}{|c|c|c|c|c|}
\hline \multicolumn{5}{|l|}{ Unit Root Test: Summary } \\
\hline \multicolumn{5}{|l|}{ Sample: $2000-2011$} \\
\hline Method & Statistic & Prob.* & $\begin{array}{l}\text { Cross- } \\
\text { Sections }\end{array}$ & Obs. \\
\hline \multicolumn{5}{|l|}{ Série: Crédito Pessoa Jurídica } \\
\hline (1)Levin, Lin \& Chu t & -133.084 & 0.0000 & 27 & 243 \\
\hline (1)Breitung t-stat & -323.415 & 0.0006 & 27 & 216 \\
\hline (2)Im, Pesaran and Shin W-stat & -279.037 & 0.0026 & 27 & 243 \\
\hline (2)ADF - Fisher Chi-square & 111.024 & 0.0000 & 27 & 243 \\
\hline (2)PP - Fisher Chi-square & 204.348 & 0.0000 & 27 & 270 \\
\hline \multicolumn{5}{|l|}{ Série: Preferência Pela Liquidez } \\
\hline (1)Levin, Lin \& Chu t & -188.127 & 0.0000 & 27 & 243 \\
\hline (1)Breitung t-stat & -123.866 & 0.1077 & 27 & 216 \\
\hline (2)Im, Pesaran and Shin W-stat & -500.963 & 0.0000 & 27 & 243 \\
\hline (2)ADF - Fisher Chi-square & 159.079 & 0.0000 & 27 & 243 \\
\hline (2)PP - Fisher Chi-square & 233.527 & 0.0000 & 27 & 270 \\
\hline \multicolumn{5}{|l|}{ Série: Selic } \\
\hline (1)Levin, Lin \& Chu t & -0.87449 & 0.1909 & 27 & 243 \\
\hline (1)Breitung t-stat & 0.80010 & 0.7882 & 27 & 216 \\
\hline (2)Im, Pesaran and Shin W-stat & 0.74844 & 0.7729 & 27 & 243 \\
\hline (2)ADF - Fisher Chi-square & 319.862 & 0.9926 & 27 & 243 \\
\hline (2)PP - Fisher Chi-square & 148.900 & 0.0000 & 27 & 270 \\
\hline \multicolumn{5}{|l|}{ Série: Depósitos à vista } \\
\hline (1)Levin, Lin \& Chu t & -877.881 & 0.0000 & 27 & 243 \\
\hline (1)Breitung t-stat & -221.787 & 0.0133 & 27 & 216 \\
\hline (2)Im, Pesaran and Shin W-stat & -207.032 & 0.0192 & 27 & 243 \\
\hline (2)ADF - Fisher Chi-square & 941.101 & 0.0006 & 27 & 243 \\
\hline (2)PP - Fisher Chi-square & 260.693 & 0.0000 & 27 & 270 \\
\hline \multicolumn{5}{|l|}{ Série: Índice Regional de Crédito } \\
\hline (1)Levin, Lin \& Chu t & -100.590 & 0.0000 & 27 & 243 \\
\hline (1)Breitung t-stat & -303.863 & 0.0012 & 27 & 216 \\
\hline (2)Im, Pesaran and Shin W-stat & -281.797 & 0.0024 & 27 & 243 \\
\hline (2)ADF - Fisher Chi-square & 112.193 & 0.0000 & 27 & 243 \\
\hline (2)PP - Fisher Chi-square & 215.779 & 0.0000 & 27 & 270 \\
\hline \multicolumn{5}{|l|}{ Série: Depósitos a prazo sobre passivo } \\
\hline (1)Breitung t-stat & -609.827 & 0.0000 & 27 & 216 \\
\hline (2)Im, Pesaran and Shin W-stat & -0.91714 & 0.1795 & 27 & 243 \\
\hline (2)ADF - Fisher Chi-square & 678.164 & 0.0979 & 27 & 243 \\
\hline (2)PP - Fisher Chi-square & 933.304 & 0.0007 & 27 & 270 \\
\hline
\end{tabular}


Continuação

\begin{tabular}{lcccc}
\hline Method & Statistic & Prob.* & $\begin{array}{c}\text { Cross- } \\
\text { Sections }\end{array}$ & Obs. \\
\hline Série: Ativo sobre PIB & & & & \\
(1)Levin, Lin \& Chu t & -825.241 & 0.0000 & 27 & 243 \\
(1)Breitung t-stat & -809.978 & 0.0000 & 27 & 216 \\
(2)Im, Pesaran and Shin W-stat & -0.58560 & 0.2791 & 27 & 243 \\
(2)ADF - Fisher Chi-square & 603.528 & 0.2571 & 27 & 243 \\
(2)PP - Fisher Chi-square & 147.527 & 0.0000 & 27 & 270 \\
\hline Série: Crédito Pessoa Física & & & & \\
(1)Levin, Lin \& Chu t & -421.105 & 0.0000 & 27 & 243 \\
(1)Breitung t-stat & 0.38518 & 0.6499 & 27 & 216 \\
(2)Im, Pesaran and Shin W-stat & 0.70406 & 0.7593 & 27 & 243 \\
(2)ADF - Fisher Chi-square & 470.912 & 0.7358 & 27 & 243 \\
(2)PP - Fisher Chi-square & 115.375 & 0.0000 & 27 & 270 \\
\hline
\end{tabular}

Notas: Grupo (1): Null: Unit root (assumes common unit root process).

Grupo (2): Null: Unit root (assumes individual unit root process).

* Probabilities for Fisher tests are computed using an asympotic Chi-square distribution.

All other tests assume asymptotic normality.

Tabela C2

Variáveis Instrumentais

\begin{tabular}{|c|c|}
\hline Brasil & $\begin{array}{l}\text { ln_cpj(-1), constante, } \operatorname{lnpl} 400410160(-1 \text { até }-4), \operatorname{lnselic}(-1 \text { até }-6) \text {, } \\
\operatorname{lndv} 412(-1 \text { até }-5), \operatorname{lndpp}(-1 \text { até }-5), \operatorname{lnatpib}(-1 \text { até }-5), \operatorname{lncpf}(-1 \text { até }-5) \text {. }\end{array}$ \\
\hline Sudeste & 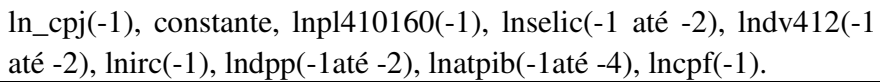 \\
\hline Sul & $\begin{array}{l}\text { ln_cpj(-1), constante, } \operatorname{lnpl} 410160(-1 \text { até }-2) \text {, lnselic(-1 até }-3) \text {, } \\
\text { lndv412(-1 até }-3), \operatorname{lnirc}(-1 \text { até }-2), \operatorname{lndpp}(-1 \text { até }-3) \text {, lnatpib(-1), } \operatorname{lncpf}(- \\
\text { 1). }\end{array}$ \\
\hline Nordeste & $\begin{array}{l}\text { ln_cpj(-1), constante, } \operatorname{lnpl} 410160(-1 \text { até }-3), \ln \operatorname{lic}(-1 \text { até }-3) \text {, } \\
\operatorname{lndv} 412(-1 \text { até }-3), \operatorname{lnirc}(-1 \text { até-3), } \operatorname{lndpp}(-1 \text { até }-3), \operatorname{lnatpib}(-1 \text { até }-4) \text {, } \\
\operatorname{lncpf}(-1 \text { até }-6) \text {. }\end{array}$ \\
\hline Norte & $\begin{array}{l}\text { ln } \operatorname{cpj}(-1), \text { constante, } \operatorname{lnp} 1410160(-1 \text { até }-3), \operatorname{lnselic}(-1 \text { até }-3) \text {, } \\
\operatorname{lndv} 412(-1 \text { até }-3), \operatorname{lnirc}(-1 \text { até }-3), \operatorname{lndpp}(-1 \text { até }-3), \operatorname{lnatpib}(-1 \text { até }-3) \text {, } \\
\operatorname{lncpf}(-1 \text { até }-4) \text {. }\end{array}$ \\
\hline C Oeste & 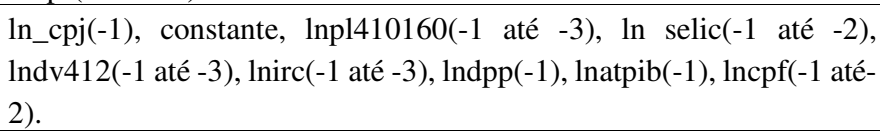 \\
\hline
\end{tabular}

Fonte: Elaboração dos autores. 